\title{
1. Happiness and wellbeing: past foundations, modern evidence and future paths
}

\author{
Luigino Bruni, Dalila De Rosa and \\ Alessandra Smerilli
}

The modern approach to the economics of happiness can be reconduced to the impressive work known as the 'Easterlin paradox'. At the beginning of the seventies the economist Richard Easterlin observed that, even though within each country higher incomes were associated with higher levels of happiness, in a country over time average levels of happiness do not increase as the average income increases. In other words, the very rich are happier than the very poor, but as the country gets richer happiness remains almost constant. The evidence was first proposed in his original work for the US during the period 1946-70 (Easterlin 1974) and then during the period 1972 to 2002 (Easterlin 2005) when the gross domestic product (GDP) in the United States almost doubled while happiness remained constant. In a more recent paper (Easterlin 2015) the author confirmed the validity of the paradox using US data in the period 1972-2014.

This evidence suggests that, beyond a certain income level required to meet basic needs, the so-called subsistence level, additional income doesn't lead to additional happiness. Individual wellbeing is made of a broader set of factors (health, relations, life sense), other than pure income, which need to be accounted for in order to define a worthwhile life. Indeed, it is worth remarking that, in a modern sense, the economics of happiness can no longer be confined to the evaluation of subjective or psychological wellbeing, but also has to encompass the whole intellectual and political movement known as going beyond GDP and its implications in terms of the measurement and analysis of quality of life $(\mathrm{QoL})$.

In this sense, the last decades have seen growing attention to measuring what makes life worthwhile both from a subjective and an objective point of view. The awareness of the limits of GDP as a measure for wellbeing has risen, and since 2007 the debate on going beyond GDP has been placed at the frontiers of both the academic and political agenda. The Easterlin paradox, 
the capability approach (CA) and the Stiglitz-Sen-Fitoussi Commission, opened the door to a new perspective centered on the pursuit of people's wellbeing. Notably it implied effort on the methodological side, namely the design of appropriate and robust measures and the analysis of the determinants of wellbeing, but also effort on the philosophical side, that is the inquiry into the real meaning and the ethical borders of happiness, wellbeing and quality of life. Not least, political effort to embed such novel discussion in the political debate. Indeed, after the Stiglitz-Sen-Fitoussi Report (2009) numerous attempts and initiatives to depict quality of life arose at the national and international level: the OECD Better Life Index, Eurostat Quality of Life Indicators, Canadian Index of Well Being, Measuring Australia's Progress, measuring national wellbeing in the UK, the Italian BES (Equitable and Sustainable Wellbeing), just to mention a few. And also the current experience of the Sustainable Development Goals goes in this direction.

This is to say, despite the enormous progress this stream of research has made, the debate is still modern and the aim of this book is to guide the reader over the historical roots of the economics of happiness, the measurement issues, the political implications and the empirical applications, which have led the debate over the years and opened room for further and future improvements.

\subsection{HISTORICAL AND PHILOSOPHICAL PERSPECTIVES OF THE ECONOMICS OF HAPPINESS}

Economics has taken two long centuries to rid itself of the 'dismal science' label and to gain a legitimate standing in society. Finally, today, not even the most critical observers can convince us that economic variables such as income, wealth or employment are not important objectives for a good life. Who can deny the evidence that wealthier people usually enjoy better health, longer life spans, lower infant mortality rates and greater access to goods, services and education? From the enjoyment of such benefits it should take just one short step to affirm that, on average, those who possess more are happier than those who possess less.

Moreover, it is not difficult to agree with the thesis that it is very hard to be happy and live a good life under extreme poverty. On the basis of these ethical justifications, political economy, along its journey, began to investigate the means for living well. It became known as the 'science of wealth', with the 'hope that poverty and ignorance may gradually be extinguished' and 'that all should start in the world with a fair chance of leading 
a cultured life, free from the pains of poverty and stagnating influences of excessive mechanical toil' (Marshall 1890: 3-4).

There is no need to start our history of happiness in this introduction from Aristotle or from ancient philosophy. Modernity has a rich enough history of the concept of happiness in relation to economics. In Chapter 5, written by Luigino Bruni, one can see Malthus's ideas about happiness and his criticism to Smith. The young Malthus felt the need to analyze directly how and under which conditions riches could be transformed into happiness. This was the path followed by the Italian tradition of public happiness (Genovesi, Filangieri, Bianchini, etc.) (see Bruni and Porta 2003). For this reason, those economists devoted their intellectual efforts to analyze the dimensions of social life that directly affect happiness or wellbeing, such as trust, civic virtues and reciprocity. The 'transformation problem', wealth into welfare, was therefore their main concern as social scientists. The mainstream political economy left aside this transformation question. In the Cambridge tradition after Malthus (1798) we find both a special attention to the relation between means (wealth) and end (happiness), and the same ambiguity of Malthus due to the gap between the methodological claims and the real content of economic theory.

But it is impossible to reconstruct the evolution of the idea of happiness in economics without taking into account Utilitarianism, built around the golden rule: 'the greatest happiness for the greatest number'. In Bentham's idea of happiness we immediately see that in his system happiness is equal to 'pleasure', as it comes straight from the very first lines of An Introduction to the Principles of Morals and Legislation: 'Nature has placed mankind under the governance of two sovereign masters, pain and pleasure' (Bentham 1789: 11).

The Benthamite vision of happiness can therefore rightly be called psychological hedonism, having an individualistic nature; people are depicted as seekers of happiness/pleasure. This psychological feature is essential to the Utilitarian programme in which social happiness is seen only as an aggregation, a sum of individual pleasures.

J.S. Mill, who on happiness diverges deeply from Bentham and from his father, James, in his Utilitarianism explicitly states that in early Utilitarianism there was an identification between pleasure and happiness: 'By happiness is intended pleasure' (Mill 1861: 210).

The other key word of Bentham is 'utility' (from which the term 'Utilitarianism' came), and the 'principle of utility' (inherited from Beccaria's Dei delitti e delle pene) is stated appropriately, in the first page of his Introduction, as the 'foundation of the present work' (Bentham 1789: 11). In all his works the words happiness, pleasure and utility are used interchangeably as different ways of expressing the same basic concept of 
Utilitarianism. In Chapter 1 of An Introduction to the Principles of Morals and Legislation he wrote that by utility he meant 'that property in any object, whereby it tends to produce benefit, advantage, pleasure, good or happiness' (Bentham 1789: 12).

With Bentham the distinction between end (happiness) and means (wealth) disappeared, and happiness/pleasure also became the direct end of economic actions. Bentham's approach to happiness, therefore, is far from either the classical vision of happiness (from Aristotle to Genovesi) and the Cambridge tradition that kept the distinction between happiness (the final end) and wealth.

Bentham's methodological project, as is well known, nurtured economics, thanks mainly to the works of Jevons and Edgeworth. Most of the leaders of the new economics based their subjectivist approach to economics on a hedonistic philosophy. In Edgeworth's early works up to Mathematical Psychics (Edgeworth 1881), the Utilitarian and hedonist philosophy had a great impact. To him happiness means pleasure, and maximizing happiness means maximizing pleasure (Edgeworth 1881: 7, 16).

Jevons (1871) defined economics as the science of utility, explicitly stating his acceptance of the Utilitarian philosophy of Bentham (Robbins 1998: 262). Happiness entered neoclassical economics fully identified with utility, the new subject of the new economics. Jevons not only states the old Utilitarian thesis that happiness is related to utility, but also that economics is the 'calculus of pleasures and pain' (Jevons 1871: 'Introduction'). To Jevons pleasures are different 'only in degree, not in kind' (Schabas 1990: 39). Economics deals with the 'lowest' ones and he does not exclude the fact that men can renounce pleasures coming from the economic domain for the sake of ethical or superior pleasures, but, as Bentham's, his ethical rule is to maximize the sum of pleasures, both individually and socially. In the theory he states:

The theory which follows is entirely based on a calculus of pleasure and pain and the object of economics is to maximize happiness by purchasing pleasure as it were, at the lowest cost of pain. (Jevons 1871: 91)

For British marginalist economists, economics became the science of the direct analysis of happiness/pleasure. The domain of economics was no longer 'wealth' but happiness/pleasure directly. While the classical economists were dealing with objective, external aspects ('material prerequisites'), with Jevons or Edgeworth economics came back to a 'subjective' approach, the domain of economics is inside man's mind.

Contemporary rational choice theory (based on the preferencesatisfaction approach) is, from a methodological point of view, a continu- 
ation of the Benthamite approach: 'The analysis assumes that individuals maximize welfare as they conceive it' (Becker 1996: 139). Contemporary rational choice theory is far from the classical/neoclassical economists and very close to Bentham or Jevons (more than they thought: if we consider Hicks' and Samuelson's battle against hedonism in economics in the 1930s). Why? First, like Jevons the domain of economics is 'maximizing' pleasure (preferences); second, the place of pleasure has been taken by preferences-satisfaction, but the core elements of the Utilitarian approach are still there:

1. The domain of economics is no more wealth or economic welfare (the material prerequisites) but to directly bring about happiness, which can be translated into concepts such as pleasure (old marginalists), ordinal utility or preferences (Hicks), or choices (Samuelson).

2. The tools utilized for studying the 'means' (maximization, quantitative calculus, instrumental rationality) are now used for specifically studying 'happiness'.

After Bentham happiness/pleasure became the object of economics: therefore, it is not true that happiness is not central in neoclassical economics. The reductionism of happiness/eudaimonia to utility/pleasure is the real break point in the history of happiness in economics: the distinction between material prerequisites and happiness, Cambridge's and classical political economy's cornerstone, has been lost.

Recently, however, other economists, psychologists or philosophers, such as Sen, Kahneman or Nussbaum, criticize a 'subjective' approach to the relationship of income/happiness, claiming that happiness cannot be measured on the basis of subjective evaluations. Sen and Nussbaum, in an Aristotelian approach, remind us that happiness must be translatable into the 'good life'. Then happiness has to be measured in terms of capabilities and functionings, human rights and freedom. As Sen notes:

As Aristotle noted at the very beginning of the Nicomachean Ethics (resonating well with the conversation between Maitreyee and Yajnavalkya three thousand miles away), "wealth is evidently not the good we are seeking; for it is merely useful and for the sake of something else'. If we have reasons to want more wealth, we have to ask: What precisely are these reasons, how do they work, on what are they contingent and what are the things we can 'do' with more wealth? In fact, we generally have excellent reasons for wanting more income or wealth. This is not because, typically, they are admirable general-purpose means for having more freedom to lead the kind of lives we have reasons to value. The usefulness of wealth lies in the things that it allows us to do - the substantive freedom it helps us to achieve. But this relation is neither exclusive (since there 
are significant influences on our lives other than wealth) nor uniform (since the impact of wealth on our lives varies with other influences). It is as important to recognize the crucial role of wealth determining living conditions and the quality of life as it is to understand the qualified and contingent nature of this relationship. (Sen 2000: 14)

Sen's thought emerges like an underground (carsic) river that has been flowing for years, carrying with it the conviction that happiness is a matter of politics. It began its course with Aristotle, re-emerged to cross the Middle Ages (Thomas Aquinas) and civic humanism (fifteenth-century Tuscany), and again to irrigate the period of Enlightenment in Scotland (Smith) and Italy. In the mid-eighteenth century in Milan and Naples, men like Muratori, Genovesi, and Verri drank from it and articulated a vision of economics into a science of 'public happiness'. We do not believe that political economists must tell people how to be happy - happiness remains a subjective matter and everyone must find his or her own way - but work only to create the objective conditions for a good living, which make a happy life possible, and maybe 'complicating economics' in order to spot non-intentional mechanisms (treadmills) or externalities. And although we recognize that psychological mechanisms are operating, which tend to subjectively neutralize improvements in material conditions, economic theory can orientate policy.

\subsection{METHODS FOR THE ECONOMICS OF HAPPINESS}

In the spirit of policy orientation, the last decade has seen growing literature in economics, social science and development studies on the measurement of happiness, wellbeing and quality of life. Yet, even though these concepts pursue the same objective of understanding wellbeing and human development with multidisciplinary tools, they certainly differ (Bruni et al. 2008). Indeed, if on one side, subjective wellbeing refers to the self-reported status of being well and it is methodologically grounded in the well-known happiness approach (HA), on the other side, the objective evaluation of wellbeing aims at identifying those factors and statuses objectively considered to be important for a worthwhile life and it grounds in the CA.

In the context of the CA, Amartya Sen moved not few critics to subjective wellbeing. First, individuals may be driven by adaptations, adjusting their aspirations downwards or upwards to reflect respectively hardship or new opportunities (Comim et al. 2008; Clark et al. 2008). Second, since perceptions depend on individuals' position, influencing beliefs, understanding and decisions, the concept of positional objectivism cannot be overlooked (Sen 1992). Third, subjective measures may risk providing self- 
regarding metrics and unreliable results for inter-individual comparison (Bruni et al. 2008). According to the CA, the capability of being happy constitutes one of the most important aspects of life and there are very good reasons for valuing it. However, happiness has to be considered as one of the capabilities in the capabilities list, whereas overall quality of life has to be assessed in terms of the capability to achieve valuable functionings (Nussbaum and Sen 1993: 27) and the set of functionings needs to be normatively defined.

On the contrary, the HA critics the paternalistic spirit embedded in the CA and it affirms that the best way to assess individual wellbeing is just asking people how well they feel. Yet, the HA covers very different aspects (Samman 2007) than pure 'people asking' or individual emotional self-reporting. Indeed, there are eudemonic measures (psychological wellbeing) and hedonic measures (subjective wellbeing). The latter distinguish between the cognitive component of life satisfaction and the positive and negative affect components of happiness. These measures come from survey questions which ask, for example, 'On the whole, are you satisfied, fairly satisfied, not very satisfied or not at all satisfied with the life you lead?' or 'Taken all together, how would you say things are these days would you say that you are very happy, pretty happy, or not too happy?' These questions are getting common in many international surveys such as the Eurobarometer Surveys, the US General Social Surveys, the World Values Surveys and the Gallup pool Surveys, just to mention some. Yet, these capture both the emotional part and the cognitive evaluation of subjective wellbeing and the stability of such measures has been widely debated in the literature. According to Frey and Stutzer (2002), the measures of subjective wellbeing/happiness, prove to be consistent and reliable and also reported subjective wellbeing is quite stable and rather sensitive to changing life circumstances (see Diener et al. 1999).

Eudemonic measures are instead grounded in positive psychology and include other aspects of a person's psychological processes. In particular, sound literature focused on the concept of good psychological functioning refer to 'flourishing' or 'eudemonic' wellbeing (Huppert 2009; Clark and Senik 2011; Ryan and Deci 2006), which goes beyond the respondent's reflective evaluation and emotional states to focus on the functioning and the realization of the person's potential. Several psychometric scales are proposed for the measurement of psychological wellbeing or in this case of 'flourishing' (see Hone et al. 2014 for a full discussion). Among these, Diener et al. (2010) created the Flourishing Scale as a summary measure of psychological functioning in a eight-item format (Purpose/meaning, Positive relationships, Engagement, Social contribution, Competence, Self-respect, Optimism, Social relationships). Similarly, Huppert and So 
(2013) tested a flourishing index on a sample of 43000 Europeans in the European Social Survey, identifying three main factors: (1) 'positive characteristics' (comprising emotional stability, vitality, optimism, resilience and self-esteem); (2) 'positive functioning' (comprising engagement, competence, meaning, and positive relationships); and (3) 'positive appraisal' (comprising life satisfaction and positive emotion).

In this eudemonic perspective, a possible overlapping of the two approaches is understandable: on one side the CA attaches great importance to issues of autonomy and agency (Sen 1985) on the other eudemonia meant as a commitment to a set of goals provides a sense of personal agency and a sense of structure and meaning to daily life (Diener et al. 1999: 284). According to Comim et al. (2008), 'eudemonic informational spaces' can provide clear guidance in terms of what both approaches can additionally offer.

From a strictly technical and methodological viewpoint, a wide range of data collection methods and statistical techniques have been used in empirical applications to assess wellbeing in the sense of quality of life. In this context, a widely recognized practice, until now, has been to consider subjective wellbeing as a dimension of overall wellbeing. In particular, among the non-statistical methods ${ }^{1}$ for assessing quality of life, there is the use of a dashboard of indicators and composite indicators. The Dashboard of Indicators applies a 'standard one-dimensional measure to each dimension' (Alkire et al. 2011) and because it is collected through the use of the best data source for each particular indicator it provides a rich amount of information allowing for a better impact assessment of specific policies. In this context, objective and subjective measures of wellbeing coexist and subjective wellbeing is considered as one of the aspects of overall wellbeing. This is the case for the Millennium Development Goals, the Sustainable Development Goals and the numerous national attempts to create similar informational frameworks. The use composite indicator overcomes the dashboard's heterogeneity and the weakness in communicability, converting the set of indicators into a real number. Still, the aggregation process imposes set relative weights on different indicators making this process vulnerable to the risk of arbitrariness. In both methods the procedure implies the setting of the normative framework, namely the need to define which factors (dimensions) capture a worthwhile life and which do not. Hence the risks of paternalism and arbitrariness are issues to be tackled.

On the other hand, among the statistical techniques the idea is to identify the joint distribution of achievements based on different methodologies, which statistically define the space of quality of life. To this purpose the use of micro-data is required in which information on each dimension 
is available for each unit of analysis. It is the case of (1) fuzzy set theory (Betti and Verma 2008; Chakravarty 2006; Martinetti 1994; 2000; 2009; Qizilbash 2006; Roche 2008); (2) multivariate data reduction techniques (Schokkaert and Van Ootegem 1990; Balestrino and Sciclone 2001; Kalsen 2000; Hirschberg et al. 2001; Lelli 2001; Neff 2007); (3) regression analysis and structural equation modeling (Kuklys 2005; Krishnakumar 2007; Krishnakumar and Ballon 2008; Di Tommaso 2007; Wagle 2009; De Rosa 2017).

\subsection{EMPIRICAL APPLICATIONS AND POLICY IMPLICATIONS IN THE ECONOMICS OF HAPPINESS}

Hand in hand with the setting of measurement methodologies, many scholars offered deep investigation into the dynamics which make a life worthwhile.

In particular, with respect to both subjective wellbeing and psychological wellbeing, several empirical applications analyzed the so-called determinants of happiness, life satisfaction and life sense. In this context the outcome subjective measure is considered as the individual utility function depending on many life factors, both context-related and individual-related; this is income, employment, inequality, but also marital status, fertility dynamics, social relations, relational goods and physical and mental health, just to mention the most explored relations. Similarly, with respect to quality of life many empirical applications tried to disentangle the trade-off and the interlinkages among the different dimensions of quality of life and analyzed the individual and contextual factors determining a certain level of life achievement. In this context the outcome measure is generally a composite measure or the result of some aggregation techniques, hence the empirical applications follow two levels of analysis: (1) the analysis of the relations among the different dimensions and the contribution each dimension gives to the overall composite measure, and (2) the analysis of the factors, others than those included in the composite measure, which affect quality of life.

Going deep into the debate of what makes a life worthwhile, empirical and theoretical literature showed the strong correlation between different forms of social capital and wellbeing: as a matter of fact, civil virtues and growth are positively correlated (Fukuyama 2001) and civically engaged people tend to be happier (Morrow-Howell et al. 2003), and have a greater sense of purpose in life (Greenfield and Marks 2004). Moreover, individuals located in places with higher levels of trust report higher levels of subjective wellbeing (Helliwell and Putnam 2004; Helliwell and Wang 2010; Bartolini 
et al. 2013) and higher levels of institutional trust determine better outcomes in subjective wellbeing (Hudson 2006). Similarly, more social interactions, relational activities and volunteering were found to significantly increase happiness and life satisfaction (Helliwell and Putnam 2004; Becchetti et al. 2008; Bartolini and Sarracino 2014; Colombo et al. 2018). In particular, a strong positive link emerges between relational goods and happiness, where relational goods, more than social capital, emphasize identity and motivation in personalized (face-to-face) interactions (Bruni and Stanca 2008). Also in the field of family studies great attention was devoted to family dynamics and wellbeing. Some scholars found that married people tend to be happier and more satisfied, with a higher level of purpose in life, optimism and energy and displaying a better wage premium and financial resources than single individuals (Cohen 1988; Gove et al. 1990; Stutzer and Frey 2006; Blanchflower and Oswald 2004; Bierman et al. 2006). Other scholars studied how children affect their parents' wellbeing. In the latter context the evidence is mixed: some found a positive relationship between parenthood and subjective wellbeing, with parents reporting higher levels of happiness, life satisfaction, self-esteem, positive emotions and meaning in life (Stutzer and Frey 2006; Haller and Hadler 2006; Hansen et al. 2009; Angeles 2010; Nelson et al. 2013; Aassve et al. 2012); while others highlighted a significant and positive effect on happiness only for the first child (Kohler et al. 2005). On the other hand, some researchers reported that having children is negatively related to subjective wellbeing and that the negative relation is mostly explained by the negative impact on financial satisfaction (Stanca 2012; Beja 2015; Bhargava et al. 2014). With respect to health and wellbeing, researchers extensively investigated such a relationship, becoming increasingly aware of the complex mutual interdependencies it encompasses (see Deaton 2008; Gwozdz and Sousa-Poza 2010). More specifically, bad mental health conditions were found to lead to much stronger decreases in life satisfaction than bad physical health conditions (Binder and Coad 2013). While physical activities, both in terms of frequency and volume, were found to be essential factors in the relationship between physical activities and happiness, numerous studies support the evidence that a small change in physical activity makes a difference to happiness (Zhang and Chen 2019). On the other hand, some applications highlighted that higher levels of happiness lead to increased physical activity (Baruth et al. 2011) and similarly that both subjective health satisfaction and eudemonic wellbeing indicators have to be considered as reliable predictors of future health outcomes (Becchetti et al. 2018; Becchetti et al. 2019).

With respect to the economic dimension of wellbeing and its relation to subjective wellbeing, Easterlin (2015) highlighted how rising unemployment is inversely related to life satisfaction. Similarly, some scholars 
investigated the link between income inequality and happiness, pointing out that increasing income inequality is consistently negatively related to wellbeing (Bartolini and Sarracino 2015; Bartolini et al. 2017; Mikucka et al. 2017) and that income inequality is a good explanation for the Easterlin paradox, that is to say economic growth does not always translate to an increase in happiness (Oishi and Kesebir 2015).

This is to say, in the recent past such evidence sheds light on the power the perspective of wellbeing has in informing public policy as in ensuring the effectiveness of social policies to shape individual life satisfaction.

\subsection{THE CONTENT OF THE BOOK}

The book is organized into three sections, each depicting a pillar of the economics of the happiness: (1) the historical and philosophical foundations of the debate; (2) the methodological and measurements issues and its political implications; and (3) the empirical applications and the debate on what determines a happy life.

Bruno S. Frey opens the discussion in Chapter 2, recalling the contribution of happiness research as part of modern economics and social psychology and designing the future of happiness research. According to the author, due to the large number of studies published, diminishing marginal insights begin to be observable, yet it is to be expected that future happiness research will pursue such well-trodden paths.

In Chapter 3 Jeffrey Sachs recollects the ancient roots of happiness, back to Aristotle, in the form of eudaimonia, and reconnects such a conception to modern psychology and neuroscience. Also Maurizio Pugno, in Chapter 4, focuses on the eudaimonic side of wellbeing, by discussing the objective/ subjective dichotomy, the greater robustness of eudaimonia with respect to hedonism and the advantages of the policy implications of eudaimonia.

In Chapter 5 Luigino Bruni offers the perspective of civil economy, the southern spirit of capitalism and the account of Felicitas Publica, whereas Paolo Santori, in Chapter 6, completes this vision by offering the thought of Tomas Aquinas on happiness.

Chapter 7 moves on to the measurement issues and the complexity such an approach has to deal with. Filomena Maggino and Leonardo Salvatore Alaimo elaborate on complex systems and its components and report the case of wellbeing indicators as a modern example of complexity.

In Chapter 8 Easterlin, Fei Wang and Shun Wang describe the evolution of China's wellbeing in the quarter century since 1990, and suggest the likely reasons for the disparate trajectories of subjective wellbeing and GDP per capita. Chapter 9 also focuses on happiness and growth: 
Francesco Sarracino and Kelsey J. O'Connor discuss the relation between economic growth and wellbeing in Luxembourg, in the presence of generous social safety nets, increasing social capital and declining income inequality. They suggest the latter condition to be a promising starting point for designing new policies to durably improve wellbeing.

In Chapter 10 the discussion encompasses the empirical evidence the literature has to offer on the determinants of subjective wellbeing. Mario Lucchini, Egidio Riva and Luca Crivelli examine the causal effect of physical activity on the three main components of subjective wellbeing in Switzerland (i.e. life satisfaction, positive affect and negative affect) while controlling for a wide set of potential socio-demographic, health, relational and environmental confounders. Dalila De Rosa and Matteo Rizzolli, in Chapter 11, explore the role of different family types on life satisfaction and satisfaction with life domains in Italy. Then Luigino Bruni, Dalila De Rosa and Giovanni Ferri, in Chapter 12, offer cross-country empirical evidence on the role of relational capital, in the form of cooperativeness, for the promotion of happiness.

In Chapter 13, Neli Esipova, Julie Ray and Anita Pugliese use Gallup data to show results coming from the Migrant Acceptance Index, created by using subjective measures from the World Gallup Poll.

\section{NOTE}

1. Non-statistical method refers to the description of wellbeing through the use of indicators appropriately identified under a normative framework.

\section{REFERENCES}

Aassve, A., A. Goisis and M. Sironi (2012), Happiness and childbearing across Europe. Social Indicators Research, 108(1), 65-86.

Alkire, S., J. Foster and M. E. Santos (2011), Where did identification go? OPHI Working Paper 43b. September 1. http://dx.doi.org/10.2139/ssrn.2118556.

Angeles, L. (2010), Children and life satisfaction. Journal of Happiness Studies, 11(4), 523-38.

Balestrino, A. and N. Sciclone (2001), Should we use functionings instead of income to measure well-being? Theory, and some evidence from Italy. Rivista internazionale di scienze sociali, 3(561), 3-22.

Bartolini, S., E. Bilancini and M. Pugno (2013), Did the decline in social connections depress Americans' happiness? Social Indicators Research, 110(3), 1033-59.

Bartolini, S. and F. Sarracino (2014), Happy for how long? How social capital and economic growth relate to happiness over time. Ecological Economics, 108, $242-56$. 
Bartolini, S. and F. Sarracino (2015), The dark side of Chinese growth: declining social capital and well-being in times of economic boom. World Development, 74, 333-51.

Bartolini, S., M. Mikucka and F. Sarracino (2017), Money, trust and happiness in transition countries: evidence from time series. Social Indicators Research, 130(1), 87-106.

Baruth, M., D. C. Lee, X. Sui, T. S. Church, B. H. Marcus, S. Wilcox and S. N. Blair (2011), Emotional outlook on life predicts increases in physical activity among initially inactive men. Health Education \& Behavior, 38(2), 150-8.

Becchetti, L., A. Pelloni and F. Rossetti (2008), Relational goods, sociability, and happiness. Kyklos, 61(3), 343-63.

Becchetti, L., M. Bachelet and F. Riccardini (2018), Not feeling well . . true or exaggerated? Self-assessed health as a leading health indicator. Health Economics, 27(2), e153-e170.

Becchetti, L., M. Bachelet and F. Pisani (2019), Poor eudaimonic subjective wellbeing as a mortality risk factor. Economia Politica, 36(1), 245-72.

Becker, G. (1996), Accounting for Tastes. Cambridge, MA: Harvard University Press.

Beja, E. L. (2015), Direct and indirect impacts of parenthood on happiness. International Review of Economics, 62(4), 307-18.

Bentham, J. (1789), An Introduction to the Principles of Morals and Legislation, ed. by J. H. Burns and HLA Hart, London.

Betti, G. and V. Verma (2008), Fuzzy measures of the incidence of relative poverty and deprivation: a multi-dimensional perspective. Statistical Methods and Applications, 17(2), 225-50.

Bhargava, S., K. S. Kassam and G. Loewenstein (2014), A reassessment of the defense of parenthood. Psychological Science, 25(1), 299-302.

Bierman, A., E. M. Fazio and M. A. Milkie (2006), A multifaceted approach to the mental health advantage of the married: assessing how explanations vary by outcome measure and unmarried group. Journal of Family Issues, 27(4), 554-82.

Binder, M. and A. Coad (2013), Life satisfaction and self-employment: a matching approach. Small Business Economics, 40(4), 1009-33.

Blanchflower, D. G. and A. J. Oswald (2004), Well-being over time in Britain and the USA. Journal of Public Economics, 88(7), 1359-86.

Bruni, L. and P. L. Porta (2003), Economies in the Age of Newton. Natural Science and Political Economy in the Italian Enlightenment. Milan: Universita di MilanoBicocca. Mimeo.

Bruni, L., F. Comim and M. Pugno (eds) (2008), Capabilities and Happiness. Oxford: Oxford University Press.

Bruni, L. and L. Stanca (2008), Watching alone: relational goods, television and happiness. Journal of Economic Behavior \& Organization, 65(3-4), 506-28.

Chakravarty, S. R. (2006), An axiomatic approach to multidimensional poverty measurement via fuzzy sets. In A. Lemmi and G. Betti (eds), Fuzzy Set Approach to Multidimensional Poverty Measurement (pp.49-72). New York: Springer.

Clark, A. E., P. Frijters and M. A. Shields (2008), Relative income, happiness, and utility: an explanation for the Easterlin paradox and other puzzles. Journal of Economic Literature, 46(1), 95-144.

Clark, A. E. and C. Senik (2011), Will GDP growth increase happiness in developing countries? Revue d'économie développement, 19(2), 113-90.

Cohen, S. (1988), Psychosocial models of the role of social support in the etiology of physical disease. Health Psychology, 7(3), 269-97. 
Colombo, E., V. Rotondi and L. Stanca (2018), Macroeconomic conditions and well-being: do social interactions matter? Applied Economics, 50(28), 3029-38.

Comim, F., M. Qizilbash and S. Alkire (eds) (2008), The Capability Approach: Concepts, Measures and Applications. Cambridge: Cambridge University Press.

De Rosa, D. (2017), Capability approach and multidimensional well-being: the Italian case of BES. Social Indicators Research, 140(1), 125-55.

Deaton, A. (2008), Income, health, and well-being around the world: evidence from the Gallup World Poll. Journal of Economic Perspectives, 22(2), 53-72.

Di Tommaso, M. L. (2007), Children capabilities: a structural equation model for India. The Journal of Socio-Economics, 36, 436-50.

Diener, E., E. M. Suh, R. E. Lucas and H. L. Smith (1999), Subjective well-being: three decades of progress. Psychological Bulletin, 125(2), 276-302.

Diener, E., D. Wirtz, W. Tov, C. Kim-Prieto, D. W. Choi, S. Oishi and R. BiswasDiener (2010), New well-being measures: short scales to assess flourishing and positive and negative feelings. Social Indicators Research, 97(2), 143-56.

Easterlin, R. A. (1974), Does economic growth improve the human lot? Some empirical evidence. In Nations and Households in Economic Growth (pp. 89-125). London: Academic Press.

Easterlin, R. A. (2005), Feeding the illusion of growth and happiness: a reply to Hagerty and Veenhoven. Social Indicators Research, 74(3), 429-43.

Easterlin, R. A. (2015), Happiness and economic growth: the evidence. In Global Handbook of Quality of Life (pp. 283-99). Dordrecht: Springer.

Edgeworth, F. Y. (1881), Mathematical Psychics. London: Kegan.

Frey, B. S. and A. Stutzer (2002), What can economists learn from happiness research? Journal of Economic Literature, 40(2), 402-35.

Fukuyama, F. (2001), Social capital, civil society and development. Third World Quarterly, 22(1), 7-20.

Gove, W. R., C. B. Style and M. Hughes (1990), The effect of marriage on the well-being of adults: a theoretical analysis. Journal of Family Issues, 11(1), 4-35.

Greenfield, E. A. and N. F. Marks (2004), Formal volunteering as a protective factor for older adults' psychological well-being. The Journals of Gerontology Series B: Psychological Sciences and Social Sciences, 59(5), S258-S264.

Gwozdz, W. and A. Sousa-Poza (2010), Ageing, health and life satisfaction of the oldest old: an analysis for Germany. Social Indicators Research, 97(3), $397-417$.

Haller, M. and M. Hadler (2006), How social relations and structures can produce happiness and unhappiness: an international comparative analysis. Social Indicators Research, 75(2), 169-216.

Hansen, T., B. Slagsvold and T. Moum (2009), Childlessness and psychological well-being in midlife and old age: an examination of parental status effects across a range of outcomes. Social Indicators Research, 94(2), 343-62.

Helliwell, J. F. and R. D. Putnam (2004), The social context of well-being. Philosophical Transactions of the Royal Society of London. Series B: Biological Sciences, 359(1449), 1435-46.

Helliwell, J. F. and S. Wang (2010), Trust and well-being (No. w15911). National Bureau of Economic Research.

Herbst, C. M. and J. Ifcher (2016), The increasing happiness of US parents. Review of Economics of the Household, 14(3), 529-51.

Hirschberg, J. G., E. Maasoumi and D. J. Slottje (2001), Clusters of attributes and well-being in the USA. Journal of Applied Econometrics, 16, 445-60. 
Hone, L. C., A. Jarden, G. M. Schofield and S. Duncan (2014), Measuring flourishing: the impact of operational definitions on the prevalence of high levels of wellbeing. International Journal of Wellbeing, 4(1), 62-90.

Hudson, J. (2006). Institutional trust and subjective well-being across the EU. Kyklos, 59(1), 43-62.

Huppert, F. A. (2009). Psychological well-being: evidence regarding its causes and consequences. Applied Psychology: Health and Well-Being, 1(2), 137-64.

Huppert, F. A. and T. C. So (2013), Flourishing across Europe: application of a new conceptual framework for defining well-being. Social Indicators Research, 110(3), 837-61.

Jevons, W. S. (1871), The Theory of Political Economy. New York: Penguin Books.

Kalsen, S. (2000), Measuring poverty and deprivation in South Africa. Review of Income and Wealth, 46, 33-58.

Kohler, H. P., J. R. Behrman and A. Skytthe (2005), Partner + children = happiness? The effects of partnerships and fertility on well-being. Population and Development Review, 31(3), 407-45.

Krishnakumar, J. (2007), Going beyond functionings to capabilities: an econometric model to explain and estimate capabilities. Journal of Human Development, 8(1), 39-63.

Krishnakumar, J. and P. Ballon (2008), Estimating basic capabilities: a structural equation model applied to Bolivia. World Development, 36(6), 992-1010.

Kuklys, W. (2005), Amartya Sen's Capability Approach: Theoretical Insights and Empirical Applications. New York: Springer.

Lelli, S. (2001), Factor analysis vs. fuzzy sets theory: assessing the influence of different techniques on Sen's functioning approach. Kath. Univ., Department Economie, Center for Economic Studies.

Malthus, Th.R. (1798), An Essay on the Principle of Population. London: Macmillan.

Marshall, A. (1890), Principles of Economics. London: Macmillan.

Martinetti, E. C. (1994), A new approach to evaluation of well-being and poverty by fuzzy set theory. Giornale degli economisti e annali di economia, 7(9), 367-88.

Martinetti, E. C. (2000), A multidimensional assessment of well-being based on Sen's functioning approach. Rivista internazionale di scienze sociali, 2, 207-39.

Martinetti, E. C. (ed.) (2009), Debating Global Society: Reach and Limits of the Capability Approach. Milan: Fondazione Giangiacomo Feltrinelli.

Mikucka, M., F. Sarracino and J. K. Dubrow (2017), When does economic growth improve life satisfaction? Multilevel analysis of the roles of social trust and income inequality in 46 countries, 1981-2012. World Development, 93, 447-59.

Mill, J. S. (1861). (1969), Utilitarianism. In J. M. Robson (ed.), Collected Works of John Stuart Mill (Vol. 10, pp. 203-59). Toronto: University of Toronto Press.

Morrow-Howell, N., J. Hinterlong, P. A. Rozario and F. Tang (2003), Effects of volunteering on the well-being of older adults. The Journals of Gerontology Series B: Psychological Sciences and Social Sciences, 58(3), S137-S145.

Neff, D. F. (2007), Subjective well-being, poverty and ethnicity in South Africa: insights from an explanatory analysis. Social Indicators Research, 80, 313-41.

Nelson, S. K., K. Kushlev, T. English, E. W. Dunn and S. Lyubomirsky (2013), In defense of parenthood: children are associated with more joy than misery. Psychological Science, 24(1), 3-10.

Nussbaum, M. and A. Sen (eds) (1993), The Quality of Life. Oxford: Oxford University Press. 
Oishi, S. and S. Kesebir (2015), Income inequality explains why economic growth does not always translate to an increase in happiness. Psychological Science, 26(10), 1630-38.

Qizilbash, M. (2006), Philosophical accounts of vagueness, fuzzy poverty measures and multidimensionality. In A. Lemmi and G. Betti (eds), Fuzzy Set Approach to Multidimensional Poverty Measurement: Economic Studies in Inequality, Social Exclusion and Well-being, vol. 3. Boston, MA: Springer.

Robbins, L. (1998), A History of Economic Thought. The LSE Lectures, ed. by S. G. Medema and W. J. Samuels. Princeton: Princeton University Press.

Roche, J. M. (2008), Monitoring inequality among social groups: a methodology combining fuzzy set theory and principal component analysis. Journal of Human Development, 9(3), 427-52.

Ryan, R. M. and E. L. Deci (2006), Self-regulation and the problem of human autonomy: does psychology need choice, self-determination, and will? Journal of Personality, 74(6), 1557-86.

Samman, E. (2007), Psychological and subjective well-being: a proposal for internationally comparable indicators. Oxford Development Studies, 35(4), 459-86.

Schabas, M. (1990), A World Ruled by Numbers: William Stanley Jevons and the Rise of Mathematical Economics. Princeton: Princeton University Press.

Schokkaert, E. and L. Van Ootegem (1990), Sen's concept of the living standard applied to the Belgian unemployed. Louvain Economic Review, 56(3-4), 429-50.

Sen, A. (1985), Well-being, agency and freedom: The Dewey lectures 1984. The Journal of Philosophy, 82(4), 169-221.

Sen, A. (1992), Inequality Reexamined. Oxford: Oxford University Press.

Sen, A. (2000), Development as Freedom. New York: A. Knopf.

Stanca, L. (2012), Suffer the little children: measuring the effects of parenthood on well-being worldwide. Journal of Economic Behavior \& Organization, 81(3), $742-50$.

Stiglitz, J. E., A. Sen and J. P. Fitoussi (2009), Report by the commission on the measurement of economic performance and social progress.

Stutzer, A. and B. S. Frey (2006), Does marriage make people happy, or do happy people get married? The Journal of Socio-Economics, 35(2), 326- 47.

Wagle, U. (2009), Multidimensional Poverty Measurement: Concepts and Applications, vol. 4. New York: Springer.

Zhang, Z. and W. Chen (2019), A systematic review of the relationship between physical activity and happiness. Journal of Happiness Studies, 20(4), 1305-22. 